work and skill, of professional responsibilities, ethics, and independent judgement, is as baneful as it is fashionable. In another form it pervades the Consultative Document issued in May by the Health Department, again with its emphasis on managers, though in that case external. ${ }^{3}$ But if nursing is to oifer an attractive career in its later stages to married women as well as single, to part-time as well as whole-time, it must allow them to nurse patients without suffering the jibe that they are "interfering" as the Salmon report puts it. The proper care of patients depends on nursing, not on administration. Likewise, the attractions of nursing as a career depend on the opportunities it offers to care effectively for the sick. This is chiefly a personal matter into which good administration-entirely laudable though it is-enters only to a small extent. If patients are to continue receiving the skilled attention they have hitherto enjoyed, advancement in the career of nursing must largely remain, as it does in medicine, in clinical practice.

${ }^{1}$ Report of the Committee on Senior Nursing Staff Structure (Chairman, B. Salmon), Ministry of Health and Scottish Home and Health Department. London, H.M.S.O., 1966 .

2 Department of Health and Social Security, Annual Report, 1970. London, H.M.S.O., 1971 .

${ }^{3}$ British Medical fournal, 1971, 2, 481.

\section{Urinary Tract Infection Presenting as Jaundice}

Several reports of an association in young infants between urinary infection and jaundice have appeared over the last decade, but have failed to excite much attention on this side of the Atlantic. In Britain a paper ${ }^{1}$ in the B.M.F. in 1967 re-emphasized the importance of jaundice as a presenting sign of urinary tract infection in infancy and childhood which had remained forgotten since the description of three cases by E. Gorter and G. O. E. Lignac ${ }^{2}$ as far back as 1928.

The usual clinical picture is of a young infant who is failing to thrive, losing weight, lethargic or irritable, and suffering from fever, jaundice, and moderate hepatomegaly. This year S. H. Ng and J. R. Rawstron ${ }^{3}$ described six cases all arising in early infancy. These were confined to male babies, four of whom had positive blood cultures but normal intravenous pyelograms, which have been features of American cases. ${ }^{4}$ The majority of cases have been recorded among young infants, but the condition should not be overlooked in childhood. A. B. Arthur and B. D. R. Wilson ${ }^{1}$ described an illness superficially resembling infectious hepatitis in a 12-year-old girl, whose condition remitted after treatment of her urinary infection, but who became jaundiced once again when this relapsed, finally recovering after a further course of treatment with another antibiotic.

Hepatocellular impairment is considered the main factor in the production of the jaundice. G. Neale and colleagues $^{6}$ had access to clinical data, biochemical tests of liver function, and biopsy material. They described pathological changes in adult patients who presented with pyrexia of unknown origin and were later found to be suffering from extrahepatic bacterial infections. Though none of their patients was jaundiced, there were profound disturbances of liver function, which might have been erroneously interpreted as having their origin in the liver or biliary tract.
Liver biopsy showed a nonspecific reactive hepatitis with an increase in concentration of Kupffer cells and some infiltration of the portal tracts with inflammatory cells. Portions of the liver sent for culture were sterile, though blood cultures were positive in some at the time of biopsy. Had antibiotics not been given it is reasonable to suppose that more severe histological changes and jaundice would have supervened, as in patients dying of bacterial infection in the pre-antibiotic era.

J. Bernstein and A. K. Brown, ${ }^{7}$ recording cases in infants of jaundice with sepsis which included pyelitis, found similar histological changes of variable degree in specimens of liver taken from post-mortem material. Since the impairment of liver function has no relationship to specific organisms it would not, in the case of urinary tract infections, be necessary to implicate "hepatotoxins" formed by Gram-negative bacilli. Fever, either artificially induced as hyperthermia or in heat stroke, may of itself damage the liver and produce jaundice, ${ }^{8}$ but, though they were febrile, hyperpyrexia was not a feature of those infants in whom the urinary tract was involved.

Haemolysis plays a part in the production of the jaundice, even necessitating blood transfusion at times. ${ }^{5} 9 \mathrm{Ng}$ and Rawstron describe a peripheral blood picture of polychromasia, spherocytosis, burr cells, and nucleated red cells reminiscent of the haemolytic uraemic syndrome. In the older textbooks a fatal infection associated with haemolysis, severe icterus, and haemoglobinuria was sufficiently well recognized to merit the name of Winckel's disease. ${ }^{10}$ The presence of bilirubin in the urine indicates that the jaundice is not entirely due to haemolysis. Cholestasis as such is probably not an important factor, but in association with dehydration, haemolysis, and liver impairment it plays a part in the overall syndrome. Poor elementary hygiene may be a predisposing factor as in the cases of $\mathrm{Ng}$ and Rawstron, whose patients were babies of immigrant parents in social grade V. Most of the other series appear to be of similar socio-economic background.

R. A. Seeler and K. Hahn, 5 citing eight reported series totalling 88 cases, found a male predominance of 3 to 1 in contrast to the usual pattern of female preponderance found in older children with demonstrable anomalies of their urinary tracts. Speculation on the source of infection has been unrewarding. A. Y. Sweet and E. Wolinisky ${ }^{11}$ and J. F. Kenny and colleagues ${ }^{4}$ referred to their series as "outbreaks," but no similar numbers have been reported in this country. Specific strains of escherichia were isolated in two Baltimore hospitals, ${ }^{4}$ and the possibility of a pyelopathogenic strain was considered, but on the evidence that hypothesis must be discarded. Though they are frequently associated with positive blood cultures, large numbers of pus cells in the urine denote a pyelonephritis rather than a bacteriuria, which may accompany septicaemia. The primary site and mode of entry have also defied elucidation. Umbilical sepsis, which may ascend the umbilical veins to the liver or descend via umbilical arteries to infect the urine, would offer a neat explanation, but is without any supporting evidence.

The diagnostic importance of associating jaundice with urinary tract infection is obvious. Several deaths were reported in earlier series, ${ }^{4} 79$ and others may have occurred when the true nature of the disease was overlooked. $\mathrm{Ng}$ and Rawstron rightly stress the early recognition of urinarytract infection with renal impairment, for the jaundice may divert investigations into other channels, resulting in a fatal delay in beginning treatment. These reports have a simple 
but important message: urinary investigation is an essential examination in any infant or child presenting with jaundice.

1 Arthur, A. B., and Wilson, B. D. R., British Medical fournal, 1967, 1, 539. 2 Görter, E., and Lignac, G. O. E., Archives of Disease in Childhood, 1928, 3, 232.

${ }^{3}$ Ng, S. H., Rawstron, J. R., Archives of Disease in Childhood, 1971, 46, 173.

4 Kenny, J. F., Medearis, D. N., jun., Klein, S. W., Drachman, R. H. and Gibson, L. E., Fournal of Pediatrics, 1966, 68, 530

Seeler, R. A., and Hahn, K., American fournal of Diseases of Children $1969,118,553$

Neale, G., Caughey, D. E., Mollin, D. L., and Booth, C. C., British Medical fournal, 1966, 1, 382.

7 Bernstein, J., and Brown, A. K., Pediatrics, 1962, 29, 873.

8 Herman, R. H., and Sullivan, B. H., jun., American fournal of Medicine, $1959,27,154$

${ }^{9}$ Hamilton, J. R., and Sass-Kortsak, A., fournal of Pediatrics, 1963, 63, 121.

10 Winckel, F., Deutsche medizinische Wochenschrift, 1879, 24, 303.

${ }^{11}$ Sweet, A. Y., and Wolinisky, E., Pediatrics, 1964, 33, 865.

\section{Treatment with Growth Hormone}

Widespread interest in the use of human growth hormone followed M. S. Raben's ${ }^{1}$ successful treatment of a 17-yearold boy with pituitary failure. During the past decade the results of several studies on the effects of long-term growth hormone therapy have been published. Human pituitary glands obtained post mortem are still the only useful source of growth hormone, and schemes for collecting such glands are operating in a number of countries. The Medical Research Council's Human Pituitary Hormone Subcommittee is responsible for collection of pituitary glands and the distribution of the hormone in the United Kingdom. At present about 75 patients in this country are receiving growth hormone treatment.

The indications for long-term growth hormone therapy are now fairly clearly defined. With the possible exception of occasional cases of hypoglycaemia ${ }^{2} 3$ it now appears that the only patients who are likely to derive real benefit from such treatment are children who are abnormally small as a result of deficiency of growth hormone, the deficiency occurring either as an isolated defect or as part of a more general anterior pituitary failure. Early hopes that growth hormone might be of value in the management of a variety of disorders associated with failure to grow have not been fulfilled. Though acceleration of growth has been reported in patients with Turner's syndrome, ${ }^{4}$ achondroplasia, ${ }^{5}$ Silver's syndrome, ${ }^{6}$ and constitutional short stature, ${ }^{7}$ the effects have been inconsistent and poorly sustained, and it is now widely accepted that growth hormone therapy is of no help to such patients.

While deficiency of growth hormone can often be suspected on clinical grounds, it is essential that the diagnosis is established as firmly as possible if prolonged periods of ineffective and wasteful therapy are to be avoided. During recent years radioimmunoassay methods for growth hormone have become more widely available, and estimation of its level in the plasma after stimuli such as insulininduced hypoglycaemia ${ }^{8}$ or infusion of arginine ${ }^{9}$ has largely replaced diagnostic tests based on the acute metabolic effects of growth hormone. ${ }^{10}$ An absent or impaired production of growth hormone in the plasma during two or more such provocative tests provides strong evidence of complete or partial deficiency of it.

With few exceptions ${ }^{11}$ good results have been obtained in the long-term therapy treatment of most patients deficient in growth hormone. During the early phases of treatment acceleration of growth can be expected, and growth rates between $8 \mathrm{~cm} /$ year and $12 \mathrm{~cm} /$ year are common. At this time the subcutaneous fat oft $' n$ diminishes. Rapid growth does not continue indefinitely. and the rate slowly declines to normal or below-nurmal levels. As a result the patient may not fully reach his "expected" height, particularly when treatment has been long delayed. When treatment is discontinued, growth slows down, often to below the pretreatment rate, but reintrodu :tion of treatment leads to further acceleration of growtl:. Bone maturation occurs during treatment, but disproportionate advance in bone age, a feature of androgen-induced growth, is not seen. In a few older patients with isolated deficiency of growth hormone treatment appears to have initiated puberty. ${ }^{12}$

The treatment regimen which allows the most efficient use of the hormone is still to be determined. Good responses have been obtained with a weekly dose of hormone as small as $2.5 \mathrm{mg},{ }^{13}$ but in most centres higher doses have been used. In general, most patients have been treated with twice- or thrice-weekly injections of hormone, but weekly administration has also been reported to be effective. ${ }^{13}$ It is still uncertain whether patients with complete anterior pituitary failure require thyroid supplements, ${ }^{14}$ 15 but it is generally agreed that corticosteroid supplements should be withheld, as relatively small doses of cortisone may reduce the response to treatment. ${ }^{16}$

Growth hormone therapy has been remarkably free from side effects. While anorexia and oliguria were reported during early studies on the acute metabolic effects of growth hormone in man, ${ }^{17}$ they have not been a problem during long-term therapy. Growth hormone has a diabetogenic action, but impaired carbohydrate tolerance has not been reported as a result of the long-term treatment of growthhormone-deficient children. The low blood sugar values commonly found in such patients return to normal as a result of treatment and symptomatic hypoglycaemia is relieved. ${ }^{18} 19$ A number of patients with craniopharyngioma have been treated with growth hormone after partial resection of the tumour; there is no evidence to suggest that such treatment accelerates growth of any residual tumour. Occasionally the patient's rate of growth returns to normal after surgical resection of a craniopharyngioma ${ }^{20}$ and growth hormone therapy is then not indicated.

In some series of patients treated with growth hormone a high incidence of anti-growth-hormone antibodies has been found. $14 \quad 152122$ In most cases the antibodies have been of low titre and do not appear to have been of clinical significance. Rashes and other evidence of hypersensitivity have not been noted, and the patients have continued to respond to treatment. In a minority of patients very high antibody titres have developed, and in many of these cases growth hormone was no longer effective. ${ }^{14} \quad 15 \quad 22 \quad 23$ In some instances the antibody titre fell when treatment was discontinued, and further growth hormone therapy was successful. ${ }^{22} 24$ In others the high antibody titres persisted and treatment had to be abandoned. 2224 The mechanisms underlying the formation of antibody during treatment with different preparations of human growth hormone are still incompletely understood. Chemical changes of the hormone may occur during extraction or lyophilization ${ }^{25}$ and may account for its antigenicity. However, additional factors may be responsible for the high antibody titres found in a minority of patients. Recently R. Illig ${ }^{24}$ described four children with a familial form of growth hormone deficiency who developed very high anti- 